\title{
Women's Participation in Seed Selection and Production in The Informal Seed System: The Case of Ebinat Woreda, South Gondar Zone of Amhara National Regional State
}

\author{
Gashaw Ayanaw
}

Department of Gender and Development Studies, Bahir Dar University, Bahir Dar, Ethiopia

\section{Article Information \\ Received: 05 April 2021 \\ Revised version received: 16 October 2021 \\ Accepted: 19 October 2021 \\ Published: 29 October 2021 \\ Cite this article as: \\ G. Ayanaw (2021) Int. J. Soc. Sc. Manage. 8(4): $445-$ 456. DOI: 10.3126/ijssm.v8i4.40496 \\ *Corresponding author \\ Gashaw Ayanaw, \\ Department of Gender and Development Studies, Bahir Dar University, Bahir Dar, Ethiopia. \\ Email: gashoaya@gmail.com \\ Peer reviewed under authority of IJSSM \\ (C) 2021 IJSSM, Permits unrestricted use under the CC-By-NC license. \\ OPEN ACCESS

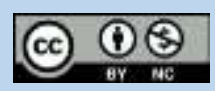 \\ This is an open access article \& it is licensed under a Creative Commons Attribution Non-Commercial 4.0 International \\ (https://creativecommons.org/licenses/by-nc/4.0/)}

Keywords: gender roles; gender division of labor; dual roles; food insecurity; decision making; on-farm seed

\section{Introduction}

\section{Background of the Study}

In poor countries, the agricultural sector is essential to growth, poverty reduction, and food security. For instance, in Sub-Saharan Africa, the agricultural sector employs 65\% of the labor force and generates about $32 \%$ of GDP growth (Christian, 2008 cited in Adeniyi, 2010). On the other hand, more than half of rural employment in Eastern Africa, where Ethiopia is located, consists of self-employed farmers many of whom are women (Adeniyi, 2010).

Recognizing the essentiality of the agriculture sector of the economy, seed sector development receives attention as seed and food security are linked together with agricultural economic development of many African countries. This is 
because good quality seed is indispensable for any food production for escalating productivity and production as well as motivating local and national economic development (Kopainsky et al., 2012; Candel, 2014).

Yet, nearly $80 \%$ of all seed used in East Africa is produced in the informal system. This means that informal seed supply is the main source of seed for most crops and farmers in developing countries and may continue to some times in the future (FAO, 2010 cited in Taylor, 2012). Similarly, Bottema and Santen (1995) pointed out that informal seed systems are commonly used by most small-scale poor farmers who operate in complex, risk prone and diverse environments. Likewise, the majority of Ethiopian smallholder farmers are largely dependent on this system mainly through farm-saved seed exchange (Atilaw and Korbu, 2011).

Globally, rural women are responsible for half of the world's food production (United Nations' report on Women, 2000; De Jong, 2000). They play an important role in producing the world's staple crops and providing labour for post-harvest activities (Adeniyi, 2010). Indeed, throughout rural Africa, women's labor input is estimated as three times than men. In performing such activities, in most African communities there are gender specific roles in agricultural production (Adeniyi, 2010).

Women disproportionately bear the burden of poverty in Ethiopia despite of their participation in the agricultural activities, which is mainly a result of the gender-based division of labor and lack of access and control over resources prescribed not only by tradition and culture, but also in the law as product of social norms particularly in the past. Women are responsible for all the household tasks parallel to their support in agriculture and livestock production. Nevertheless, they have little saying on decisions (United Nations Women's Watch, 2008; Marshall and Farahbakhsh, 2013).

CDC (2008) cited in Rediet (2011) noted that the Amhara Region is known in crop production. About $85 \%$ of its economically active population is engaged in such sector. Nonetheless, some parts of the region (north east) are prone to shortage of rain fall and food for many months in the year. From the total 126 woredas, $64(51 \%)$ of them including Ebinat are food insecure. Ebinat woreda located in drought prone areas of the ANRS is characterized by erratic rainfall, land degradation, chronic food insecurity and poor production potential (SERA/DPPC project, 2000).

\section{Statement of the Problem}

Holmes and Jones (2010) pointed out that women represent almost half of the world population in numeric terms. For example, in Ethiopia, the proportion of male to female ratio is almost equal, 0.97 male/female (ECSA, 2007; Garenne, 2017). However, women have been marginalized in many sectors especially in decision making process (Caracalla, 2009). According to Caracalla (2009), women have no sufficient place in the society and issues of marriage and divorce which always determine by their male counterpart. In most parts of the world, particularly in developing countries, women are excluded and marginalized in the major economic arena at large and have negligible voice apart from delivering their labor.

Women's low decision-making power, particularly in developing countries, is more pronounced at household level (Chirnet and Mulugeta, 2002; Kopainsky et al., 2012; Marshall and Farahbakhsh, 2013). In other words, women have lower status in the society compared to that of men, which has an adverse impact on the overall health status and conditions of women in developing countries. The problems of gender inequalities discussed so far have very much prevalent in and relevant to Ethiopia which has a patriarchal society that keeps women in a subordinate position as noted by Chirnet and Mulugeta (2002).

But what the past studies failed is that they did not give due emphasis on some specific issues that need to be searched so as to know women's share in such issues. Among those issues that so far has not been assessed very well is women's voice in seed selection and their participation in the process of seed production. For instance, Dawit et al. (2012) noted that women in rural areas of Ethiopia at large have low participation in most decisions of seed production. But, this study overlooks to see the condition of women in food insecure areas and specific gender roles and gender division of labor in seed production and selection.

Cognizant of such fact, the researcher conducted this study which aimed at assessing the nature of women's participation in selecting seeds and their role throughout its production process in the informal seed system at local level where farmers' livelihood depends on agriculture, and production is not more than hand to mouth. In nutshell, it is important to take intervention measures and to have scientific evidence for the question to what extent women are playing roles and what tasks are belongs to women and men in the informal seed system.

\section{Objectives of the Study}

The general objective of this study was to assess women's participation in seed selection and production process in Ebinat woreda. The study intends to pursue the following specific objectives under this general objective:

* Examine the extent of women's participation in seed selection and production;

* Examine the degree of participation of women among themselves in selection and production of seed;

* Identify the tasks do women and men play in seed selection and production; 
* Investigate the socio-cultural factors determining women's participation in seed selection and production processes.

\section{Research Methodology and Description of the Study Area}

\section{Description of the Study Area}

\section{Location and Topography}

Ebinat is located in between $11^{\circ}$ and $12^{\circ}$ north latitude, and $37^{\circ}$ and $38^{\circ}$ east longitude. It is bordered by North Gondar Zone (East Belesa woreda) on the north; Farta woreda in the south; North Wollo Administrative Zone of Bugna woreda, and Waghimra Zone of Dihana woreda on the east; Lai Gayint woreda in the south east; and Libo Kemkem woreda in the west (Ebinat Woreda Communication Affair, 2013).

\section{Landscape and Agro-ecology}

The woreda covers a total land area of 249,427.1 sq. kms of which 169,784.1 (68\%) comprise cultivable land. Topographically, $45 \%$ of the woreda is mountainous, $35 \%$ hilly, $15 \%$ plain and $5 \%$ is valley. Its altitude ranges from $1800 \mathrm{~m}-2150 \mathrm{~m}$ above sea level. Ebinat has three agroecological zones with 50\% kolla, 35\% Woyina Dega and $15 \%$ Dega. Moreover, the average annual rainfall ranges from $500 \mathrm{~mm}$ to $1300 \mathrm{~mm}$ (South Gondar Administrative Zone Information and Communication Office, 2011; Agegnehu, 2015; Melkegnaw, 2015).

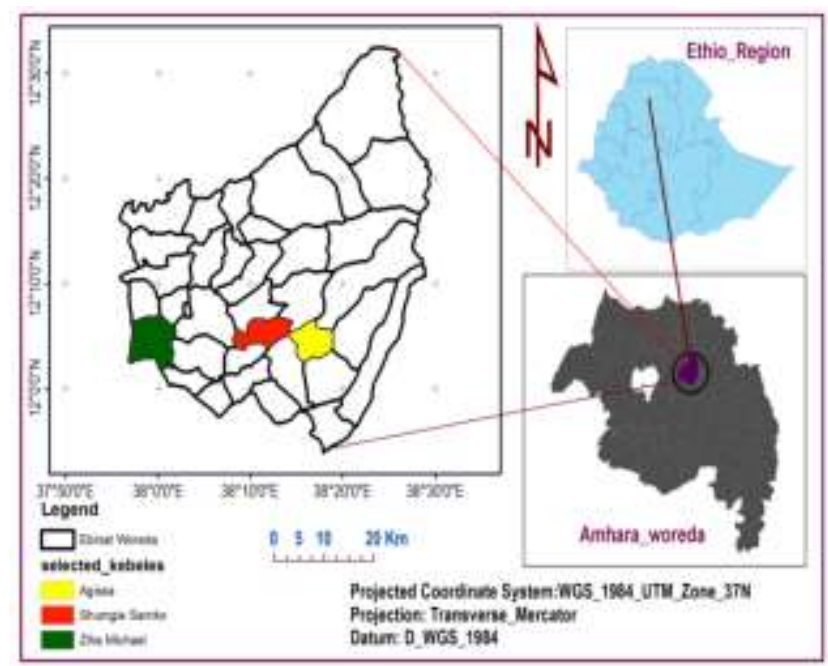

Fig. 1: Location Map of the Study Area (Ebinat Woreda and Selected Kebeles)

\section{Research Methodology}

\section{Research Approach and Design of the Study}

The study employed mixed research approach for the reason that quantitative or qualitative research method is not sufficient to address the complex social phenomena when it's treated separately. Hence, when quantitative and qualitative research methods used in combination in one study, they complement to each other and allow for a more complete analysis of the research problem (Angell \&Townsend, 2011; Creswell et al., 2006).

\section{Sampling Techniques for the Quantitative Component}

Women who are living in the rural kebeles' (35 kebeles') of Ebinat selected purposively as women know better their situation and contribution than others. From those women, the targets of this research were those who are married $(37,705)$. This is for the reason that looking the participation, decision making of women, and examining gender roles in seed selection and production needs the existence of male and female in a household. Three kebeles were selected by probability sampling-stratified random sampling-technique since the rural kebeles of Ebinat woreda are categorized in to agro- ecological zones of Dega (15\%), Woyina Dega (35\%), and Kolla (50\%). From these strata, Shumgie-sarniko, Ziha, and Agissa kebeles were selected randomly from Dega, Woyina Dega, and Kolla agro-ecological zones respectively.

\section{Sample Size and Determination}

The researcher used Cochran's (1963) formula for determine the sample size based on the real context of the study. The formula is:

$\mathrm{n}_{0=} \frac{z^{2} p q}{e^{2}}$

Where, $\mathrm{n}_{0}=$ the required numbers of sample

$\mathrm{z}=$ the desired confidence level

$\mathrm{e}=$ margin of error/precision/confidence interval

$\mathrm{p}=$ estimated variability/proportion of the population

$\mathrm{q}=1-\mathrm{p}$

Accordingly, 95\% confidence level $(\mathrm{z}=1.96)$, the maximum variability among the population $(50 \%)$, and $\pm 7.5 \%$ margin of error/confidence interval were used.

When we apply the formula,

$\mathrm{n} 0=\frac{(1.96)^{2} 0.5(1-0.5)}{(0.075)^{2}}=\frac{3.8416 \times 0.5 \times 0.5}{0.5625}=170$

Consequently, the required sampled population (170) was distributed to each of the three stratums (sampled kebeles) proportionally. Then, 45, 59, and 66 women were selected from the stratum of Kolla (Agissa), Woyina Dega (Ziha), and Dega (Shumgie-sarniko) residents respectively. Finally, the individuals involved to fill the questionnaire also selected in random sampling method from the respective kebeles.

\section{Sampling Techniques for the Qualitative Component}

The participants to give the qualitative information were Agriculture experts, Food Security officials, and Women, Youth and Children Affair officials of Ebinat woreda as well as rural women who have lived in marriage and 
relatively have experience in involving in crop production. To select the key informants, in-depth interviewees, and focus group discussants, the researcher used nonprobability sampling. Accordingly, 8 key informants, 5 indepth interviewees and 18 focus group discussants with three groups having six members were taken in line with data saturation.

\section{Data Sources and Data Collection Techniques}

The sources of data to this research were both primary and secondary sources.

\section{Methods of Data Analysis}

Both quantitative and qualitative data analysis techniques were used in this study. The data were coded, edited and entered into SPSS (Statistical Package for Social Scientists) version 20, and analyzed using descriptive and inferential statistics. On the other hand, the information that collected through KIs interviews, focus group discussions and observations were documented and analyzed textually via thematic analysis to complement the statistical results.

\section{Results and Discussion}

\section{Demographic and Socio-Economic Characteristics of Respondents,}

Regarding the age of respondents, about $42 \%$ lies in the age group of 35-44 while the age group of 55-65 accounts for
$1.8 \%$. The data revealed that the age of respondents concentrated in the middle age of the labor force. The study also indicated that about $2 \%$ of the respondents have more than 10 children while $58.8 \%$ of them have $0-4$ children (Table 1).

The other characteristic of respondents was their health situation in which the majority $(77.7 \%)$ responded that their health status was normal while some of them $(22.3 \%)$ agreed that they have certain health problems. The characteristic that high variation is shown is their residence in which more than half $(63.5 \%)$ of respondents responded as their residence is patrilocal while $13.5 \%$ of them were matrilocal residents. The result showed that in the study area a woman after marriage has little chance to live near to her family. As it can be seen in Table 1, about $37 \%$ of respondents' were illiterate while very few of them attained preparatory $(0.6 \%)$ levels of education. Among the total respondents, $38.2 \%$ of were beneficiary of safety net program while the remaining $61.8 \%$ of them were not. In other words, since the program is /was designed for food insecure woredas, it is possible to argue that $38.2 \%$ of the respondents could be grouped to chronic food insecurity.

Table 1: Demographic and Socio- Economic Characteristics of Respondents' $(n=170)$

\begin{tabular}{llll}
\hline Characteristics & Category & Frequency & Percent (\%) \\
\hline Age & $15-24$ & 17 & 10.0 \\
& $5-34$ & 54 & 31.8 \\
Number of children & $35-44$ & 71 & 41.8 \\
& $45-54$ & 25 & 14.7 \\
Number of children in terms of sex & $55-64$ & 3 & 1.8 \\
& $0-4$ & 100 & 58.8 \\
Health status & $5-9$ & 67 & 39.4 \\
Residence & More male & 3 & 1.8 \\
& More female & 66 & 38.8 \\
& equal number & 41 & 37.1 \\
& Normal & 132 & 24.1 \\
Level of education & have health problems & 38 & 77.6 \\
& Patrilocal & 108 & 22.4 \\
& Matri-local & 23 & 63.5 \\
& Neutral & 39 & 13.5 \\
& Illiterate & 62 & 22.9 \\
& Adult education & 55 & 36.5 \\
& Elementary & 38 & 22.4 \\
& high school & 5 & 2.9 \\
& Preparatory & 1 & 0.6 \\
& Others & 9 & 5.3 \\
& Yes & 65 & 38.2 \\
& No & 105 & 61.8 \\
\hline
\end{tabular}




\section{Decision Making Power of Women in Seed Selection in the Study Area}

Regarding women's involvement in seed selection, the lion share $(76.5 \%)$ of respondents are participator in seed selection whereas some $(23.5 \%)$ of them are not participant (Table 2). As it can be seen in Table 2, the majority (76.5\%) are participator in seed selection and seems important. But, the question is to what extent they are involving and on which decision making activities they are being involved? Accordingly, as it is shown in Table 2, about $21 \%$ of women's participation in seed selection is high while $44.7 \%$ of women are low and non-participant. Though the majority of women are participant in seed selection decisions, their participation is not active and overrides by their counterparts as the result shows.

The other important thing is on which areas of seed selection decisions women are active participant and on which of them they are less participant. In this regard, the data revealed that women are relatively active participant in checking the germination potential of seeds and accounts for $27 \%$ while they have low participation in deciding the amount of seed to be planted in which they have 6.5\% participation. Extent of women's participation in plowing and others are not discussed here rather summarized in Table 2.

From these, it is possible to say that women's participation in decisions regarding seed selection varies across the types of decisions where they have better saying in some areas and neglect voice on some other seed selection decisions. At the same time, one can understand the fact that women have better knowledge on the quality of seeds including their germination potential, but women have little chance to decide what amount and type of seed to be planted.

This finding is supported Owusu-Bempah (2019), as he found out that in traditional farming systems, crop diversity provides the opportunity for farmers to keep their options open where women play a bigger role than men in many cropping systems so that they frequently control seed selection and management of crop varieties and therefore; this would imply women have more knowledge of plant diversity and have an important role in the management and conservation of plant genetic resources.

Likewise, Sikod (2007) argued that crop domestication has often depended on the observational powers of women who historically have been most associated with seed selection and noticing new varieties which spontaneously appear in the field. The same author also suggested that women 'naturally' are more interested in crop diversity than men. Inconsistence to these suggestions indicated, Nuijten (2010) pointed out that gender does not seem to be a factor for how varieties are selected. Regarding the association between women's participation in seed selection and their background characteristics, the chi-square test result showed that respondents' age, greater number of children in terms of sex, and residence are statistically significant at $\mathrm{p}<0.05$. In contrast, there is no significant difference between women's education and their decision making. This seems contradictory to many findings that revealed the existence of relation between education and decision making of women in different spheres. But it is unlikely to women's involvement in seed selection due to the fact that whether women are educated or not they have indigenous knowledge and expertise on seed through experience.

Table 2: Respondents' Decision-Making Power in Seed Selection

\begin{tabular}{llll}
\hline & Category & Frequency & Percent \\
\hline Women's participation in seed selection & Yes & 130 & 76.5 \\
Extent of women's participation in seed selection & No & 40 & 23.5 \\
& Lon & 40 & 23.5 \\
& Mew & 36 & 21.2 \\
& Medium & 59 & 34.7 \\
Decision maker on the amount of seed for sowing & High & 35 & 20.6 \\
& Husband & 99 & 58.2 \\
& Wife & 11 & 6.5 \\
Responsible to check germination potential of & Both & 60 & 35.3 \\
seed & Husband & 82 & 48.2 \\
& Wife & 46 & 27.1 \\
Decision maker on re-plowing & Both & 42 & 24.7 \\
& Husband & 95 & 55.9 \\
\hline
\end{tabular}


Table 3: Respondents' Participation in Seed Production across Different Activities

\begin{tabular}{llll}
\hline & Category & Frequency & Percent \\
\hline Women's participation in seed production & Yes & 145 & 85.3 \\
Women's participation in plowing & No & 25 & 14.7 \\
& Low & 94 & 55.3 \\
Women's participation in wedding & Medium & 44 & 25.9 \\
& High & 7 & 4.1 \\
& None & 25 & 14.7 \\
Women's participation in harvesting & Low & 15 & 8.8 \\
& Medium & 27 & 15.9 \\
& High & 103 & 60.6 \\
& None & 25 & 14.7 \\
& Low & 28 & 16.5 \\
Women's participation in threshing & Medium & 90 & 52.9 \\
& High & 27 & 15.9 \\
& None & 25 & 14.7 \\
& Low & 73 & 42.9 \\
& Medium & 60 & 35.3 \\
& High & 12 & 7.1 \\
& None & 25 & 14.7 \\
& Low & 41 & 24.1 \\
& Medium & 61 & 35.9 \\
& High & 43 & 25.3 \\
& None & 25 & 14.7 \\
& Total & $\mathbf{1 7 0}$ & $\mathbf{1 0 0 . 0}$ \\
\hline
\end{tabular}

\section{Women's Participation in Seed Production in the Study Area}

The majority $(85.3 \%)$ of the respondents noted that they are participant in the process of seed production while few $(14.7 \%)$ responded that they do not have any participation in the process of seed production. Since there are different activities in the process of seed production, it is advisable to see the extent of women's participation in each activity so as to see on which activities of seed production do women have high participation and on which of the activities they are less participant.

As it is shown in Table 3, the majorities $(60.6 \%)$ of women have high participation in weeding; but, very few $(4.1 \%)$ have high participation in plowing. The result showed that plowing is usually the work belongs to men while weeding is commonly performed by women. This leads to the fact that in rural areas where agriculture is the dominant economic activity there is an unfair division of labor based on gender in which certain works belongs to male and female thereby makes women disadvantaged.

This result is consistent with the work of Adeniyi (2010) which says rural women play an important role in producing the world's staple crops and providing labour for postharvest in which most African communities have had gender specific roles in agricultural production. The same author further indicated that land clearing is normally assigned to men, while weeding and transporting crops from the farm to the home or to cooperative units are normally done by women. In relation to this, Olumakaiye and Ajayi (2000) cited in Boon et al., 2009) found out that African women including Ethiopian women perform about $80 \%$ of the transportation from farm to village; $90 \%$ of the work of hoeing and weeding; and $60 \%$ of the work of harvesting and marketing of farm products. With regard to the association between women's participation in seed production and their background characteristics, respondents' age and number of children have an association with women's participation in seed production at $\mathrm{p}<0.05$ as the chi-square result shows.

Women's Participation in Seed Storage in the Study Area Among the total respondents, $66.5 \%$ of them agreed that they are responsible for seed storage while $15.9 \%$ responded that the responsibility of seed management is the task of their husband. On the other hand, regarding the responsibility to prepare seed store, $25.9 \%$ of them are responsible for such task while $22.4 \%$ of them responded that their husbands are responsible in preparing stores for seed (Table 4).

From the result shown in Table 4, it can be understood that women have greater responsibility in managing seed though their husband has cooperation in preparing storage material for the seed to be saved from the on-farm seed production. For the question do women face problems in relation to seed storage; more than half $(61.1 \%)$ of respondents agreed that they experienced problems in relation to seed management. In relation to this, the respondents were asked to give their 
opinion and indicated the problems as shortage of seed due to using the seed for household consumptions; attacked by insects and animals like rats while storage; expiration of seed due to moisture and high temperature; lack of sufficient and safe storage there by exposed to thief; and problem of seed's inability to germinate when planted because of unsafe storage. Concerning the association of facing problems in storage of seeds and the demographic and socio-economic backgrounds of women, no association is found at $\mathrm{p}<0.05$ in all characteristics as the chi-square statistics shows. Thus, women are facing problem in storage seed regardless of their backgrounds.

\section{Women's Participation and Decision Making in Seed Exchange in the Study Area}

Regarding to women over all participation in seed exchange, $47.1 \%$ of the respondents have medium participation and followed by high $(35.9 \%)$ participation while only few (17\%) of them have low participation and therefore, women in the male headed household are active participant in seed exchange and marketing (Table 5). But, the question here has to be raised is in which activities of seed exchange women have strong saying and participation. Accordingly, women's voice in deciding on the necessity of seed exchange, and on where and from whom the seed to be exchanged is low in which decision made by women accounts $18.2 \%$ and $11.2 \%$ respectively. In contrast, regarding to under taking seed exchange, $45.3 \%$ of the respondents responded that they are responsible to make seed exchange when needed while $25 \%$ of them agreed as their husbands are responsible to do that. From this, one can understand that women's participation in seed exchange is relatively high though it is low regarding passing decision. This implies that women are responsible to give more labor to undertake seed exchange. This result confirmed with the findings made by Senait (2000) cited in Dawit et al. (2012), which says rural women have significant roles in most farm operations of seed management although their competence in decision making has been questioned.

According to Table 6, unlike to problems in seed storage, concerning the participation of women in seed exchange, kebele of respondents has an association with women's participation in seed exchange at $\mathrm{p}<0.05$. This would imply that the participation of women varies across kebeles and thereby agro-ecological zones which have different features in terms of topography and land escape.

Table 4: Respondents' Participation in Seed Storage

\begin{tabular}{llll}
\hline & Category & Frequency & Percent \\
\hline Responsible to seed & Husband & 27 & 15.9 \\
storage/management & Wife & 113 & 66.5 \\
& Both & 30 & 17.6 \\
Responsible to prepare seed store & Husband & 38 & 22.4 \\
& Wife & 44 & 25.9 \\
& Both & 88 & 51.8 \\
Problems in relation to seed storage & Yes & 69 & 61.1 \\
& No & 44 & 39.9 \\
\hline
\end{tabular}

Table 5: Women's Participation in Seed Exchange

\begin{tabular}{llll}
\hline & Category & Frequency & Percent \\
\hline Decision maker on the necessity of & Husband & 58 & 34.1 \\
seed exchange & Wife & 31 & 18.2 \\
& Both & 81 & 47.6 \\
Decision maker on where and from & Husband & 32 & 18.8 \\
whom the seed to be exchanged & Wife & 19 & 11.2 \\
& Both & 119 & 70.0 \\
Responsible to make seed exchange & Husband & 44 & 25.9 \\
& Wife & 77 & 45.3 \\
& Both & 49 & 28.8 \\
& Total & 170 & 100.0 \\
Overall condition of women's & Low & 29 & 17.1 \\
participation in seed exchange & Medium & 80 & 47.1 \\
& High & 61 & 35.9 \\
\hline
\end{tabular}


Table 6: Respondents' Problems in Relation to Seed Storage and Participation in Seed Exchange by their Demographic and Socio-Economic Backgrounds

\begin{tabular}{lllll}
\hline & \multicolumn{2}{c}{$\begin{array}{c}\text { Problems in relation to } \\
\text { seed storage }\end{array}$} & \multicolumn{2}{c}{$\begin{array}{l}\text { Women's participation in seed } \\
\text { exchange }\end{array}$} \\
\hline Characteristics & $\chi^{\mathbf{2}}$ & $\mathbf{p}$ & $\chi^{\mathbf{2}}$ & $\mathbf{p}$ \\
\hline Respondents' Age & 9.563 & 0.297 & 5.788 & .671 \\
Respondent's number of children & 4.883 & 0.299 & 5.217 & 0.266 \\
Beneficiary of safety net & 5.247. & 0.073 & 1.384 & 0.501 \\
programme & & & & \\
Greater number of children in terms & 2.431 & 0.657 & 3.364 & 0.499 \\
of sex & & & & \\
Respondent's Kebele & 3.419 & 0.490 & 13.817 & $0.008^{*}$ \\
Respondent's level of education & 17.216 & 0.070 & 4.526 & 0.921 \\
Respondent's Health status & 3.255 & 0.196 & 2.597 & 0.273 \\
Respondent's residence & 1.270 & 0.867 & 6.549 & 0.162 \\
\hline
\end{tabular}

\section{Households' Experience in Seed Shortage and Women's Contribution to Fill Seed Gaps in the Study Area}

From the total respondents, the majority $(68.2 \%)$ of them have faced seed shortage. From the result, it can be said that many households in the study area are subject to seed shortage, and they unable to save sufficient seed from their on-farm production. In this regard, head of Ebinat Woreda Food Security Office stated that there is frequent shortage of seeds in the woreda particularly for seed varieties that resist diseases and drought. This finding is consistent with the study conducted by DPPC/SERA project (2000), which revealed that,

"Food shortage is the major challenging problems
causing misery among the population of Ebinat
woreda. The comparison of total crop production
and annual food need of the households clearly
shows the severity of food deficits. Production per
capita is very low compared to the recent DPPC
standard of $180 \mathrm{~kg}$ per person per year. According
to DPPC's study in 2000, more than half of the
households (61.2\%) considered their stock as
insufficient for the remaining period of the year,
while 33.4 percent were out of reserve."

In relation to this, a question was posed in such a way that who is responsible in finding solutions for seed shortages? About $72 \%$ of the respondents indicated that both wife and husband are responsible for finding solutions for seed shortage where as $12 \%$ of them agreed that their husband is responsible for such task (Table 7). The other issue raised was the coping mechanisms taken when households faced seed shortage. As it is shown in Table 7, about $38 \%$ of the respondents used borrowing seed which is mainly accessed from local merchants, neighbors, relatives, friends, families, churches, and local governments' agricultural inputs office borrowings. Whereas, very few (12.9\%) of them used other options including dubie from local traders, buying seed from grain market, leaving certain plot of land without covering of crops, selling live stocks (oxen, goats, sheep), seed exchange, and using the land jointly.

From the results indicated, it can be said that women have nearly equal participation in finding coping mechanisms for seed shortage. However, in return borrowings, women have less participation especially in re-turn money related borrowings. That is why from the total respondents the majority $(47.5 \%)$ of them responded that their husband is responsible to return borrowed money while only $5 \%$ of them agreed that wives are responsible to such tasks (Table 7). Here, the important thing that observed from these results is that women have less access and control on money related issues and mostly engaged on activities that need more labor in terms of energy and time.

Respondents' level of education, residence and health status have significant association with their experience in seed shortage at $\mathrm{p}<0.05$. This implies that women's experience in facing problem of seed shortage varies depending on their level of education, health status and residence. Regarding the coping mechanisms households could take, only respondents' residence has significant association at $\mathrm{p}<0.05$ as the chi-square result indicated. This would suggest that the solutions households apply in case seed shortage occurs vary depending on households' residence; otherwise, no association between other women's socio-economic characteristics and the coping mechanisms the household would take.

On the other hand, regarding the responsibility of finding solutions for seed shortages in households, the chi-square result revealed that there is significant difference among women based on their health status and residence at $\mathrm{p}<0.05$ whereas there is no significant difference among respondents because of other demographic and socioeconomic backgrounds such as age, number of children, beneficiary of safety net programme, greater number of children in terms of sex, kebele, and level of education at $p<0.05$. The descriptive finding earlier showed that the greater percentage of households are in a position to find

Full text of this paper can be downloaded online at www.ijssm.org/ \& http://nepjol.info/index.php/IJSSM/issue/archive 452 
solutions jointly-husband and wife-in case seed shortage happened; yet here, one can understand the fact that this condition depends on women's actual health status and residence; and therefore, varies across women in line with such variables.

\section{Women's Participation in Seed Production and its Relation to Domestic Tasks in Male Headed Households in the Study Area}

As stated earlier more than $85 \%$ of the respondents were participants in seed production. Surprisingly, about $72 \%$ of women are responsible to domestic tasks while they participate in seed production. However, about $1 \%$ of the respondents stated that their husbands are responsible to domestic tasks whilst women participate in seed production (Table 8 ). The remaining $13.7 \%$ of the respondents use other options (housemaids and children). This result supports the study conducted by Senait (2000) cited in Dawit et al. (2012) which revealed that women in Ethiopia play multiple and overlapping roles, which in turn put pressure on their health, food security, productivity and potential contribution to improved human welfare and economic development. Another writer Tsegaye (1997) as cited in Boon et al. (2009) also stated that the productive and reproductive roles of females in society, termed as "double-day" roles, results in a heavier workload for females than males.

This shows that women are bearing both the burden of domestic tasks and production of seeds which exposes them for different problems. For instance, of the total respondents, who were responsible to domestic tasks and production, more than half $(55.2 \%)$ have faced problems due to triple roles. Among the problems mentioned by them over exploitation of labor, losing due attention for children's caring, feel unhealthy and unhappy, lack of leisure, over load of tasks, stress, low life expectancy, male's attitude for domestic tasks being low, and difficult to accomplish the domestic tasks timely were notable ones cited by the majority of the respondents.

Table 7: Respondents' Experience in Seed Shortage and their Contribution to Fill Seed Gaps

\begin{tabular}{llll}
\hline & Category & Frequency & Percent \\
\hline Women's experience in seed & Yes & 116 & 68.2 \\
shortage & No & 54 & 31.8 \\
& Total & 170 & 100.0 \\
Responsible in finding solutions for & Husband & 14 & 12.1 \\
seed shortage & Wife & 18 & 15.5 \\
& Both & 84 & 72.4 \\
& Total & 116 & 100 \\
Coping mechanisms for seed & borrowing & 40 & 34.5 \\
shortage & money & & \\
& borrowing seed & 44 & 37.9 \\
& gift from & 17 & 14.7 \\
& relatives & & 12.9 \\
& other options & 15 & 100 \\
Responsible in return when & Total & 116 & 47.5 \\
borrowed money & Husband & 19 & 5.0 \\
& Wife & 2 & 47.5 \\
& Both & 19 & 100.0 \\
\hline
\end{tabular}

Table 8: Respondents' Participation in Seed Production and its Relation to Domestic Tasks

\begin{tabular}{llll}
\hline & Category & Frequency & Percent \\
\hline Responsible to domestic tasks while & Husband & 1 & 0.7 \\
women participate in seed production & Wife & 105 & 71.9 \\
& Both & 20 & 13.7 \\
& Other options & 20 & 13.7 \\
Facing problems due to dual works & Total & 146 & 100.0 \\
& Yes & 58 & 55.2 \\
& No & 47 & 44.8 \\
\hline
\end{tabular}


Table 9: Working domestic tasks while women participate in seed production by respondents' demographic and socio-economic backgrounds

\begin{tabular}{|c|c|c|c|c|c|c|}
\hline \multirow[b]{2}{*}{ Characteristics } & \multicolumn{2}{|c|}{$\begin{array}{l}\text { Responsible in } \\
\text { Finding Solutions } \\
\text { for Seed Shortage }\end{array}$} & \multicolumn{2}{|c|}{$\begin{array}{l}\text { Responsible in } \\
\text { Working Domestic } \\
\text { Tasks While Women } \\
\text { Participate in Seed } \\
\text { Production }\end{array}$} & \multicolumn{2}{|c|}{$\begin{array}{l}\text { Facing problems due } \\
\text { to dual works }\end{array}$} \\
\hline & $\chi^{2}$ & $\operatorname{Sig}(p)$ & $\chi^{2}$ & Sig $(p)$ & $\chi^{2}$ & $p$ \\
\hline Respondent's Age & 11.235 & 0.509 & 21.371 & 0.165 & 13.861 & 0.085 \\
\hline $\begin{array}{l}\text { Respondent's number of } \\
\text { children }\end{array}$ & 10.165 & 0.118 & 15.466 & 0.051 & 6.768 & 0.149 \\
\hline $\begin{array}{l}\text { Beneficiary of safety net } \\
\text { programme }\end{array}$ & 2.113 & 0.549 & 3.385 & 0.496 & 4.095 & 0.129 \\
\hline $\begin{array}{l}\text { Greater number of children in } \\
\text { terms of sex }\end{array}$ & 5.146 & 0.525 & 7.147 & 521 & 3.329 & 0.504 \\
\hline Respondent's Kebele & 7.926 & 0.244 & 4.358 & 0.823 & 4.625 & 0.328 \\
\hline Respondent's level of education & 24.602 & 0.056 & 37.404 & $0.010^{*}$ & 32.951 & $0.000^{*}$ \\
\hline Respondent's Health status & 10.505 & $0.015^{*}$ & 20.419 & $0.000^{*}$ & 54.691 & $0.000^{*}$ \\
\hline Respondent's residence & 18.600 & $0.005^{*}$ & 17.550 & $0.025^{*}$ & 14.784 & $0.005^{*}$ \\
\hline
\end{tabular}

Regarding taking the responsibility for domestic tasks when women participate in seed production, the chi-square result indicated that there is significant difference among respondents depending on their health status, education and residence at $\mathrm{p}<0.05$ (Table 9). Thus, it is possible to argue that though the lion share of domestic tasks always belongs to women, it differs depending on women's real context like education, health, and residence. The other most important thing observed from the chi-square test is women's problem due to dual works (domestic tasks+ participation in seed production) which has significant difference at $p<0.05$ in light of respondents' education, health status and residence. Regarding this, Sikod (2007) revealed that education is increasingly becoming a major factor enabling women to break down barriers to some socialization factors giving rise to the division of household labor. Accordingly, the same author concludes that the more educated a woman is, the more likely that she would going to venture into spheres traditionally considered as male areas.

\section{Conclusion}

The study revealed that the majority of women in male headed households in the study area are participant regarding seed selection. Nevertheless, their extent of participation is at low level in seed selection tasks and decisions, and strong on activities that require investing of labor where as their voice in decision making is nearly silent. The study also found out that the lion shares of women have participation in the process of seed production. Yet, women devote differently their labor for different parts of seed production in which they intensively invest their labor on weeding and followed by exporting of seeds. In participating in seed production, no significance variation among women's health, education, wealth, and number of children in terms of sex was found at $\mathrm{p}<0.05$.

Via this study, it is proved that, in most cases, women are responsible in seed store and management in which they mainly cannot be escaped problems of seed shortage and seed expiration. More than half $(68.2 \%)$ of women are in households, which have/had faced seed shortages though the situation varies depending on women's residence, education, and health. In response to this, women have almost equal participation with their husbands in finding coping mechanisms. But, women's participation is bold in borrowing and return of commodity (seed) related options while they do have low participation in borrowing and return money. According to the study, the majority (71.9\%) of respondents are participating in seed production without sharing the domestic tasks to their husbands or other options though situations vary depending on women's level of education, health status, and residence at $\mathrm{p}<0.05$. Consequently, more than half $(55.2 \%)$ of them exposed to health-related problems.

The study explored that there are gender roles and division of labor in seed selection and production in the study area. Accordingly, roles of women in seed selection include tasks for the process of ensuring the seed quality and managing the selected seed till it planted while men expected to play roles of determining the types, varieties and the amount of seed needed for planting. Regarding seed production, in most cases, women perform weeding and harvesting whereas men expected to perform tiling and threshing tasks. 
Not only this, there are specific gender division of tasks in plowing, weeding, harvesting, and threshing of seeds.

Last, not least, though majority of women are participant in seed selection and production, their participation is not without constraints and challenges. Constraints in seed selection were backward technologies in the process of working on seed quality and storage, and lack of market access in nearby whilst constraints for women's participation in seed production were early marriage, gender roles and division of labor, and health problems which in most cases emanated from overload of tasks or triple roles of women.

\section{Recommendations}

$>$ Women's participation in seed selection is with low extent and limited saying in decision making while they intensively provide their labor in production activities of seed like weeding. Thus, so as to increase women's saying apart from their labor delivery, and to reduce unfair gendered division of tasks in production, the local government shall work on awareness creation about the importance of involving women in prominent decisions of seed selection and production and avoiding dysfunctional demarcation of roles. Women are being part of seed production processes regardless of their health problems and level of education. At the same time, they are performing the domestic tasks despite of their participation in production. Thus, women with health problems and caring many children shall get leisure and the domestic tasks should be shared by someone else. For that matter, the local government shall give trainings to men in male headed households either to share the domestic tasks or find other solutions.

$>$ Women are the direct bearer of problems in seed store and shortage which largely resulted from inaccessibility of technologies and production inputs. Therefore, the concerned body shall facilitate the provision of technologies that could overcome such problems thereby reduces the burdens of women. In relation to this, organizations working on the integration of the formal and informal seed sectors like ISSD Ethiopia shall establish local seed business cooperatives that can fill seed shortages in the woreda. In addition, the local government shall construct roads in local markets thereby it could be easier for women to participate actively in seed exchange, seed sale and other marketing activities in the local markets.

\section{Conflict of Interest}

Author declares no conflict of interest with the present study.

\section{Acknowledgements}

First and foremost, I would like to thank my adviser Arega Bazezew (PhD) for his valuable and constructive comments, which substantially contributed for the thesis to hold the right truck. My special thanks go to ISSD Ethiopia, especially ISSD Ethiopia Bahir Dar University unit, for its financial and moral supports in conducting this research. I want also to extend my gratefulness to Ebinat Woreda Women, Youth and Children Affair Officials, Ebinat Woreda Agriculture Officials, and Ebinat Woreda Food Security Officials, who supported me in collecting the necessary data for this thesis. Last, but not least, my special thanks go to all enumerators who made easier the data collection task.

\section{References}

Adeniyi L (2010) Women Farmer's and Agriculture Growth: Challenge and Perspective for Africa face the economic crisis. Poster presented at the Joint 3rd AAAE and 48th AEASA Conference, Cape Town, South Africa

Agegnehu A (2015) The Cause of Rural Household Food Insecurity and Coping Strategy: in the case of Ebinat district, South Gondar Zone, Amhara Regional State. Indria Gandhi National Open University School of Continuing Education: Addis Ababa, Ethiopia

Angell B and Townsend L (2011) Workshop for the 2011 Society for Social Work and Research annual meeting. Institute for Health: Health Care Policy and Aging Research of Rutgres: Rutgres School of Social Work.

Atilaw A and Korbu L (2011) Recent development in seed systems of Ethiopia. Improving farmers' access to seed. Ethiopian Institute of Agricultural Research: Debre Zeit Research Center: Debre Zeit: 13-30.

Boon E, Subramanian Jand Ogato G (2009) Gender Roles in Crop Production and Management Practices: A Case Study of Three Rural Communities in Ambo District,Ethiopia. Journal of Hum Ecology, 27(1):1-20: Human Ecology Department: Vrije Universiteit Brussel, Belgiumn

Bottema V and Santen K (1995) Integrating Seed Systems for Annual Food Crops Proceedings of a Workshop Held in Malang, Indonesia: available at wwww.uncapsa.org accessed on $05 / 09 / 2013$

Candel J (2014) Food security governance: a systematic literature review. Food Security 6(4): 585-601.

Caracalla A (2009) The State of Food and Agriculture: Women in Agriculture Closing the Gender Gap for Development. Food and Agriculture Organization of the United Nations: Rome

Chirnet H and Mulugeta E (2002) SIDA: Country Gender Profile Ethiopia. Addis Ababa: Ethiopia: Avaialble at 
www.hivaidsclearinghouse.Unisco.org/sa accessed on june16, 2013.

Creswell J, Shope R, Plano L and Green D (2006) How interpretive qualitative research extends mixed methods Research. Research in the Schools 13(1): 1-11.

Dawit T, Dessalegn T, Yimam A and Kefale M (2012) Extent of Rural Women Participation and Decision Making in Seed Production Activities.Vol.1 (7): Global Advanced Research Journal of Agricultural Science: Bahir Dar

De Jong G (2000) Expectations, gender, and norms in migration decision-making. Population studies 54(3): 307-319.

Ebinat Woreda Communication Affair (2013) Brusher on Profile of Ebinat Woreda. Ebinat, Ebinat Woreda

Ethiopian Central Statistical Agency (ECSA) (2007) Report of the 2007 national census available at http://en.wikipedia.org/wiki/Demographics_of_Ethiopia accessed on 11 November 2013 at 12:55.

Garenne M (2017) The enigma of Ethiopian sex ratios at birth. Journal of biosocial science 49(5): 611-622.

Holmes R. and Jone,N (2010)How to Design and Implement Gender Sensitive Social Protection Program. ODI at 50 Advancing Knowledge Shaping Policy Inspiring Practices: Overseas Development Institute.

Israel G (1992) Determining Sample Size. University of Florida: Gainesville: Retrieved on file:///c:/users/hanutechdetermining samplesize / htm : accessed on august 8/2013

Kopainsky B, Tröger K, Derwisch S and Ulli-Beer S (2012) Designing sustainable food security policies in subSaharan African Countries: how social dynamics over-ride utility evaluations for good and bad. Systems Research and Behavioral Science 29(6): 575-589.

Marshall R and Farahbakhsh K (2013) Systems approaches to integrated solid waste management in developing countries. Waste Management 33(4): 988-1003.

Melkegnaw E (2015) The Effectiveness of Productive Safety Net Program among Food Insecured Rural Households in some Selected Kebeles of Ebinat Woreda, South Gondar
Zone. University of Gondar, College of Social Sciences and the Humanities, Department of Social Anthropology Postgraduate Program in Development Anthropology

Nuijten H (2010) Gender and management of crop diversity in The Gambia. Journal of Political Ecology: case studies in history and society 17: 42-58.

Owusu-Bempah K (2019) The role of women farmers in choosing species for agroforestry farming systems in rural areas of Ghana. In Gender Issues in Farming Systems Research and Extension: (pp. 427-443): CRC Press

Rediet T (2011) Vulnerability Profile and Coping Mechanisms in Ebinat Woreda. Addis Ababa: Addis Ababa University

Sikod F (2007) Gender Division of Labour and Women's Decision-Making Power in Rural Households in Cameroon. African Development: Vol. XXXII, No.3 2007: Council for Development of Social Science Research in Africa

South Gondar Administrative Zone Information and Communication Office (2011) Brusher on profile of South Gondar Zone Woredas. Debre Tabor, South Gondar

Strengthening Emergency Response Abilities (SERA/DPPC) Project (2000). Vulnerability Profile of Ebinat Woreda (district), South Gonder Zone, Amhara Region. Prepared with support from Disaster Prevention and Preparedness Commission (DPPC)

Taylor F (2012) Integrated Seed Sector Development in Africa: A Conceptual Framework for Creating Coherence between Practices, Programs, and Policies.Vol.26 Taylor and Francis Group, LL

United Nations Women's Watch (2008) Ethiopian Action plan. Available at http//www.un.wom/wh//eth.ac/.org. Accessed on July $1 / 2013$

United Nations' Report (2000) Gender and Racial Discrimination: Report of the Expert Group. United Nations Division for the Advancement of Women: Office of the High Commissioner for Human Rights: United Nations Development Fund for Women: 21-24 November 2000, Zagreb, Croatia. 